\title{
(t)
}

\section{COOPERAÇÃO E HEGEMONIA NA DINÂMICA DO CAPITALISMO CONTEMPORÂNEO: A ORGANIZAÇÃO PRODUTIVA DO MST NO CEARÁ}

\author{
Cooperation and hegemony in the dynamics of contemporary \\ capitalism: the productive organization of MST in Ceará
}

\section{Evelyne Medeiros Pereira ${ }^{1}$}

\section{RESUMO}

O trabalho analisa as contradições existentes no processo de cooperação na produção, orientado pela perspectiva da cooperação agrícola, desenvolvido por trabalhadores vinculados ao Movimento dos Trabalhadores Rurais Sem Terra (MST) no Ceará, isso a fim de investigar os reflexos desse processona construção deexperiências que apontem para uma nova hegemonia de classe. Para tanto, a pesquisa demandoua observação de campo nas áreas de reforma agráriacom experiências no âmbito da cooperação agrícola; a análise documental e realização de entrevistas semiestruturadas aos dirigentes do Movimento, especialmente aqueles vinculados ao Setor de Produção no estado. Assim, a reflexão sobre os determinantes e as mediações que circunscrevem os processos de cooperação nos marcos do Capitalismo nos possibilitou compreender a coexistência desigual do agronegócio e da agricultura familiar como fruto do antagonismo entre capital e trabalho.

\footnotetext{
${ }^{1}$ Assistente Social. Mestre em Serviço Social pela UFPE. Professora do quadro efetivo do Curso de Serviço Social do Instituto Federal de Educação, Ciência e Tecnologia do Ceará (IFCE). E-mail: <evelyne.mp2913@gmail.com>.
} 


\section{PALAVRAS-CHAVE}

Cooperação. Hegemonia. MST.

\section{ABSTRACT}

The paper analyzes the existing contradictions in the process of cooperation in production, driven by the perspective of agricultural cooperation, developed by workers linked to the MSTin Ceará. So in order to investigate the impact of this process on building experiences that point concretely to a new class hegemony. To this end, the research gave priority to the reality of the state of Ceará, sued the observation field in areas of land reformwith experiences in the field of agricultural cooperation; document analysis and realization of semi-structured interviews to the leaders of the movement, especially those linked to the production Sector in the state.Thus, the reflection on the determinants and the mediations that limited the cooperation processes in capitalism enabled us to understand the coexistence of agribusiness and agriculture unequal family as fruit of antagonism between capital and labor.

\section{KEYWORDS}

Cooperation. Hegemony. MST.

Submetido: $15 / 7 / 2012$

Aceito: $20 / 8 / 2012$

\section{INTRODUÇÃO}

Na realidade contemporânea, tem se propagado um fenômeno que anuncia a reconfiguração da relação entre Estado e sociedade civil pautada pela "parceria" e pelo consenso. Tempos de "solidariedade" e "cooperação", de "ensinar a pescar o peixe", no qual todos têm a real possibilidade de "fazer sua parte". Este é o caminho mais indicado para, diante de um regime que prima pela "democracia", enfrentar o agravante quadro de acirramento da questão social - conjunto das expressões das desigualdades da sociedade capitalista madura (IAMAMOTO, 2004) - que caracteriza a barbárie em que vivemos, almejando "novas" possibilidades de "sustentabilidade humana" e "desenvolvimento social".

Seria de uma incrível grandeza espiritual caso não nos lembremos do antigo (e cada vez mais atual) debate com o Idealismo que ajudou a conformar e consolidar as bases do Materialismo Histórico-dialético, indicando que “[...] a produção das idéias, 
das representações, da consciência está em princípio diretamente entrelaçada com a atividade material e o intercâmbio material dos homens" (MARX; ENGELS, 2009, p. 31-32).

Dessa forma, ousamos nos situar frente ao desafio de não ficar apenas na aparência, no aspecto fenomênico, mas de merguIhar nas entranhas da realidade, de seus determinantes e das mediações sócio-históricas. Tarefa esta nada fácil, no entanto, cada vez mais necessária e urgente em tempos de crise do capital que, ao contrário do proclamado discurso "solidário", "democrático" e "pactual", exponencia na vida cotidiana o caráter mais agressivo, opressor, alienante e desumanizante do Capitalismo contemporâneo. O resultado, obviamente, é sempre a comunidade dos produtores que cobre os custos de tudo.

A meta estabelecida até 2015 pelo Programa das Nações Unidas para o Desenvolvimento (PNUD) de "[...] erradicar a extrema pobreza e a fome mundial [...] (BRASIL, 2010)", mediante ao compromisso dos 191 Estados-membros das Nações, não teve grande êxito nos últimos anos. De acordo com pesquisas divulgadas pela Organização das Nações Unidas (ONU), a riqueza mundialmente produzida continua tendo como traço marcante a concentração. Isto tendo em vista que os $20 \%$ mais ricos do mundo ficam com mais de $80 \%$ do Produto Interno Bruto (PIB) mundial, o que reflete no aumento da pobreza. Atualmente, por volta de 1 bilhão e meio da população mundial vive em condição de mera sobrevivência.

O contexto internacional apresenta algumas tendências mais relevantes. Dentre estas, a alta dos preços dos alimentos e da energia em consonância com a persistência da crise econômica mundial, sendo, hoje, acompanhada pela especulação financeira, um maior índice de consumo nos países "emergentes" e as catástrofes ambientais. Como reflexo, agravam-se as condições de vida da maioria da população, destituída de seus direitos, criando um terreno propício para o acirramento dos conflitos nos mais diversos países e regiões.

Na América Latina, segundo o documento Panorama Social da América Latina (CEPAL, 2009), no ano de 2008, a incidência da pobreza atingiu $33 \%$ da população, incluindo 12,9\% que viviam em 
condições de pobreza extrema ou indigência. Esses índices correspondem a 180 milhões da população considerada pobre e 71 milhões de indigentes, respectivamente.

No Brasil, temos uma das taxas mais elevadas de concentração de renda e propriedade fundiária, o que aprofunda as contradições entre riqueza e pobreza; classes e regiões. Sobre isto, evidenciamos que "os $10 \%$ da população ocupada com os rendimentos mais elevados concentraram $42,5 \%$ do total de rendimentos de trabaIho, enquanto os $10 \%$ com os rendimentos mais baixos detiveram 1,2\% do total das remunerações" (IBGE, 2009).

Em relação ao desemprego, embora nas últimas décadas tenha ocorrido um aumento sistemático do emprego formal e a consequente diminuição do desemprego, em geral, por intermédio de medidas anticrise desenvolvidas durante a fase expansiva do capital no Brasil, observamos que não houve avanços estruturais na sociedade brasileira. Os efeitos dessa situação têm implicado especialmente sob a população jovem e pobre, sendo ainda a sociedade brasileira atravessada pela violência e militarização como forma de criminalização da questão social. Nos últimos 10 anos, por exemplo, morreram cerca de 600 mil pessoas, em sua maioria jovens com idade entre 15 e 25 anos, fazendo com que um em cada 500 jovens não chegue aos 19 anos.

Como falar, então, de alternativas viáveis, ajustáveis na atual sociedade, diante de uma crise de tamanha proporção que demonstra claramente que os limites do capital colidem com os limites da própria existência humana? Em torno de quais interesses as "saídas solidárias" tão proclamadas, apoiadas no âmbito da "cooperação", se constituem? Para o fortalecimento e construção de qual hegemonia? De antemão, lembramosa seguinte afirmação: "[...] é justamente nesses momentos de colapso que soluções quixotescas e substitutivos são propostos com tanta paixão 'humanitária"” (MÉSZÁROS, 2009, p. 60).

Tomamos, portanto, as contradições do Capitalismo como nosso principal eixo orientador, a partir do qual traçaremos o caminho da nossa análise, centrada na relação entre cooperação e hegemonia nos marcos da sociedade contemporânea. Para tanto, identificar os projetos políticos e os conflitos de classes existen- 
tes nas iniciativas orientadas pela cooperação é de fundamental importância. Nesse sentido, centramos nossas reflexões em torno das experiências de cooperação agrícola desenvolvidas pelos trabalhadores rurais organizados no Movimento dos Trabalhadores Rurais Sem Terra (MST), nas áreas de reforma agrária do estado do Ceará, Brasil. Trata-se de um processo, fruto de pesquisa de mestrado em Serviço Social pela Universidade Federal de Pernambuco (UFPE), realizada entre os anos de 2010 e 2011, intitulada "Cooperação e hegemonia na dinâmica do Capitalismo contemporâneo: a cooperação agrícola e organização política dos trabalhadores rurais na Lagoa do Mineiro/Ceará" (PEREIRA, 2011).

Destacamos que a grande motivação dessa pesquisa deu-se a partir das contradições da realidade dos assentamentos rurais, dos entraves e potenciais existentes no âmbito da organização produtiva e política dos trabalhadores observados durante as atividades de assistência técnica, das quais fizemos parte durante, aproximadamente, dois anos, desenvolvidas pela Associação de Cooperação Agrícola do Estado do Ceará (ACACE), em convênio com o Instituto Nacional de Colonização e Reforma Agrária (INCRA) no estado. É, assim, em meio a esse solo fértil, que se tornou viável a análise aqui apresentada.

\section{A RELAÇÃO ENTRE COOPERAÇÃO E HEGEMONIA NO CAPITALISMO}

Os dilemas sobre as possibilidades de transformações mais amplas na sociedade por meio da cooperação são repostos sob "novas" bases e condições sócio-históricas do movimento de concentração e centralização do capital. Este movimento mostra-se cada vez mais forte, demandando uma intensa socialização do trabalho junto à apropriação privada da riqueza produzida, o que aprofunda o “[...] fenômeno do pauperismo [...]" (MOTA, 2008, p. 25). Isso torna esses dilemas, atravessados fundamentalmente pelo recorte de classe, cada vez mais expressivos em nosso tempo.

Nesse contexto, com o objetivo de recompor as taxas de lucro e expansão da acumulação capitalista, setores da burguesia nacional e mundial, com uma ampla aliança, têm apostado em mecanismos ideopolíticos que promovam maior adesão, consentimento, das classes a seu projeto, escamoteando a realidade de intensificação da exploração e da pauperização dos que trabalham. Re- 
ferimo-nos à relevância de um discurso de cariz liberal que vem apontado para a possibilidade de superar o atual quadro social a partir do estabelecimento das relações de "cooperação" e "solidariedade", que promovam uma efetiva "harmonia social". Diversas práticas de natureza "associativista" e "cooperativista" vêm sendo relacionadas a experiências que vão desde a cogestão empresarial a cooperativas profissionais.

Nessa lógica, é no campo da sociedade civil que a cooperação tem tido seu lugar e funcionalidade, sendo essa esfera supostamente dotada de autonomia e capacidade, por excelência, de consenso. "Este consenso, a nosso ver, vem se formando, paulatinamente, dentre outras formas, a partir das propostas participativas [...] para dar legitimidade à reforma neoliberal do Estado" (AMARAL, 2006, p. 61). No âmbito da aparência, predomina dicotomia entre a sociedade civil e o Estado.

Como vemos, esse processo tem reforçado o controle capitalista viabilizando um "novo" padrão econômico de acumulação, o que demanda adequar as estruturas burocráticas do Estado às novas exigências do capital por, principalmente, reformas, ou melhor, contrarreformas (BEHRING, 2003). Isso vem permitindo a desresponsabilização do Estado pela garantia dos direitos fundamentais, historicamente conquistados pelos trabalhadores, além de estimular a colaboração entre as classes em prol do projeto dominante. O protagonismo da sociedade civil fortalecida, mobilizada e impregnada de um "voluntarismo filantrópico" é apresentado como principal forma de enfrentar os efeitos do crescente aprofundamento das desigualdades sociais. Esse apelo à colaboração, com o propósito de legitimar as ações estatais e integrar a sociedade à ordem vigente, é uma das principais estratégias que se constrói para neutralizar os conflitos e dissimular os antagonismos entre os projetos societários.

Assim, a sociedade capitalista passa a ser lida sob a ótica da comunidade, numa regressão conservadora, que salienta os laços de coesão em detrimento das contradições, equiparando “[...] organizações com funções e significados sociopolíticos e econômicos inteiramente distintos na sociedade: as corporações empresariais, entidades combativas na defesa de direitos 
humanos e sociais, a tradicional filantropia e o voluntariado" (IAMAMOTO, 2004, p. 46).

Contraditoriamente, a cooperação tem sido também reivindicada pelas classes subalternizadas como um mecanismo de enfrentamento às refrações da questão social que recaem brutalmente sobre suas condições de vida e trabalho. Nesse sentido, com o intuito de construir alternativas viáveis ao Neoliberalismo, diversas organizações têm promovido ações nesse campo, como as experiências de cooperativas de produção e comercialização, grupos e coletivos de produtores, fábricas recuperadas, entre outras.

$\mathrm{Na}$ verdade, esse processo configura-se também como partícipe da história das organizações e resistência da classe trabalhadora, muitas delas orientadas pelo legado revolucionário do século XX. A cooperação também tem atravessado o debate e as experiências em torno das táticas e estratégias da esquerda política na perspectiva de construção de um período de "transição socialista” e, por conseguinte, de uma correlação de forças suscetível a uma hegemonia que supere a ordem burguesa. Nessa trajetória, uma das principais questões apresentadas foi (e continua sendo) a seguinte: Como transformar a cooperação numa força produtiva dos produtores livremente associados?

Assim, a história mais recente registrou um contínuo embate entre as classes que vêm forjando importantes experiências de resistência no seio da luta social. É o que demonstra o percurso que vai desde a revolta de 1839-1842, na França, dos tecelões de Lion, às experiências de produção e comercialização coletivas desenvolvidas durante o século XX na Rússia, na China, em Cuba e demais países no Leste Europeu e na América Latina, como bem caracteriza Fabrini Marcos (2010).

O legado da classe trabalhadora, especialmente no âmbito da cooperação na produção, é marcado pelo dilema Reforma ou Revolução? que toma maior relevo no século XX. Os acontecimentos desse período influenciam as mais diversas organizações de trabalhadores em todo o mundo, até hoje, que se dispuseram a empreender processos organizativos orientados para a construção de uma nova hegemonia de classe. 
Sobre esse assunto, lembramos as análises de Luxemburgo (1999) que apontavam para a impossibilidade de construir o Socialismo por meio de reformas graduais do Capitalismo, com multiplicação de cooperativas de produção e consumo, o aumento do poder sindical e a ampliação da democracia parlamentar. A autora apresenta uma contradição fundamental: os meios (sindicatos, cooperativas, reformas sociais e democratização política do Estado), historicamente, não podem suprimir a lei do valor. Daí o equívoco em considerar que se pode realizar o Socialismo pelas cooperativas e torná-las o fim ao invés de um dos meios possíveis.

Ao analisar as cooperativas, em especial as cooperativas de produção, Luxemburgo chama atenção para a sua essência híbrida dentro da economia capitalista, composta por uma pequena produção socializada dentro de uma troca capitalista. Isso, considerando que, na lógica capitalista, há uma completa dominação do processo de produção pelos interesses do capital, em face da concorrência. Luxemburgo (1999) atenta para o caso da cooperativa de produção, em que os "[...] operários vêem-se na necessidade contraditória de governar a si mesmos com todo o absolutismo necessário e desempenhar entre eles mesmos o papel de patrão capitalista" (Luxemburgo, 1999, p.81). Segundo ela, é desta contradição que morre a cooperativa de produção, "[...] quer pela volta à empresa capitalista, quer, no caso de serem mais fortes os interesses dos próprios operários" (LUXEMBURGO, 1999, p. 81).

Neste sentido, "[...] as cooperativas de produção têm de limitar-se, na melhor das hipóteses, a um pequeno mercado local [...]" tendo em vista que todos os ramos mais importantes da produção capitalista estão excluídos da cooperativa de produção. Eis porque, sem levar em consideração o seu caráter híbrido, “[...] as cooperativas de produção não podem ser consideradas uma reforma social geral [...]", pela simples razão de pressupor a sua realização geral, antes de tudo, a supressão do mercado mundial e a dissolução da economia mundial atual em pequenos grupos locais de produção e de troca, "[...] constituindo no fundo, por conseguinte, um retrocesso da economia do grande capitalismo à economia mercantil da Idade Média" (LUXEMBURGO, 1999, p. 82-83). 
Assim, é feita uma crítica central aos desdobramentos da Teoria da adaptação ao Capitalismo tendo em vista que leva a cargo toda a reforma socialista em cooperativas, "[...] de luta contra o capital de produção, isto é, contra a principal base da economia capitalista, a uma luta contra o capital comercial e, principalmente, contra o pequeno e médio capital comercial, isto é, unicamente contra pequenos ramos do tronco capitalista" (LUXEMBURGO, 1999, p. 82-83).

Desta forma, ressaltamos o equívoco que algumas organizações de trabalhadores historicamente têm enfrentado ao restringir as relações de cooperação na produção a uma forma fixa, como as cooperativas. Estas foram (e são) apenas um dos meios mais comuns de materialização e institucionalização do trabalho cooperado. O ponto central, a nosso ver, é atentarmos para os desafios do controle dos trabalhadores sobre as decisões políticas, condições e relações de trabalho. Para isso, é fundamental conceber que as experiências de cooperação não podem ser analisadas fora do contexto munido de contradições, conflitos sociais e disputa de projetos antagônicos inerentes à dinâmica capitalista de (re)produção das relações sociais. Sem essa referência, torna-se inviável pensar nas possibilidades da cooperação enquanto caminho para a construção de uma hegemonia na perspectiva desuperação da ordem do capital.

\section{O TRABALHO E A COOPERAÇÃO SOB HEGEMONIA DO CAPITAL}

Tomamos como pressuposto que a cooperação tem, antes de tudo, como principal fundamento o próprio trabalho, concebido como "[...] fonte de toda riqueza [...] ao lado da Natureza, que lhe fornece a matéria por ele transformada em riqueza [...]. É a condição fundamental de toda a vida humana [...]" (ENGELS, 2000, p. 215). É, portanto, com essa capacidade humana que se tornou possível a produção de objetos úteis, necessários à humanidade, dotados de valor-de-uso.

Esse processo, eminentemente histórico, possibilitou o desenvolvimento do ser humano enquanto ser social e, por conseguinte, uma maior complexificação das relações sociais e de suas mediações. Sobre esse ponto de vista, a cooperação, ao mesmo tempo em que foi fruto desse processo, foi, e continua sendo, elemen- 
to propulsor, como bem nos indica Engels (2000) ao retratar as transformações da espécie humana com o desenvolvimento do trabalho durante centenas de milhares de anos: "[...] o aperfeiçoamento do trabalho, contribuía para aproximar, cada vez mais, os membros da sociedade; para multiplicar os casos de ajuda mútua, de ação em comum, criando, em cada um, a consciência da utilidade dessa colaboração" (ENGELS, 2000, p. 215-217).

Nesse sentido, independente de determinado modo de produção, a cooperação compõe um importante aspecto no desenvolvimento das forças produtivas, potencializando as capacidades humanas no processo de trabalho, e vice-versa, que é eminentemente coletivo, ou melhor, social. E é por isso que "[...] quando o trabalhador coopera sistematicamente com outros, livra-se dos grilhões de sua individualidade e desenvolve as possibilidades de sua espécie" (MARX apud BOTTOMORE, 2001, p.80). Desse modo, "Marx pode argumentar que a cooperação leva à criação da força coletiva de trabalho, que é mais do que a soma das partes que a constituem" (BOTTOMORE, 2001, p. 80). Portanto, a cooperação está atrelada ao processo de (re)produção da vida social. Sobre isso, lamamoto (2009) afirma que "[...] determinado modo de produzir supõe, também, determinado modo de cooperação entre os agentes envolvidos" (IAMAMOTO, 2009, p. 17).

É, entretando, sob a vigência do modo de produção capitalista que a cooperação assume contornos radicalmente novos, passando a se desenvolver sobre as bases das contradições inerentes a essa sociedade. Dentres estas, a contradição fundamental entre capital e trabalho, sustentada na dissociação e alienação cada vez maior entre trabalhadores e a propriedade dos meios pelos quais realizam o trabalho, convertendo em assalariados os produtores diretos.

Diante disso, podemos dizer que "[...] as forças produtivas do trabalho coletivo são apropriadas pelo capital, enfrentando o trabalhador com elementos que os subjugam" (IAMAMOTO, 2009, p. 17). A cooperação do trabalho apresenta-se como capacidade do trabalho socialmente combinada sob o aspecto do trabalhador coletivo. Este, para Marx (2008, p. 388), é “[...] forma fundamental do modo de produção capitalista [...]”, valorizando o 
valor-agora, não apenas o valor-de-uso como também o valor-de-troca -, pelo aumento da produtividade com a divisão social do trabalho, além da inserção de tecnologias e diminuição do tempo socialmente necessário no processo de produção de mercadorias. Para melhor demonstrar a importância da cooperação para o Capitalismo, basta lembrar que:

[...] a produção capitalista só começa realmente quando um mesmo capital particular ocupa, de uma só vez, número considerável de trabalhadores [...]. Chama-se cooperação a forma de trabalho em que muitos trabalham juntos, de acordo com um plano, no mesmo processo de produção ou em processos de produção diferentes, mas conexos [...]. Não se trata aqui da elevação da força produtiva individual através da cooperação, mas da criação de uma força produtiva nova, a saber, a força coletiva (MARX, 2008, p. 375-379).

Assim sendo, ainda que a cooperação tenha existido nos modos de produção anteriores, é apenas no Capitalismo que ela pode ser "[...] sistematicamente explorada, graças à disponibilidade de trabalhadores assalariados que podem ser reunidos em grande número" (BOTTOMORE, 2001, p. 81). Desse modo, a força produtiva social do trabalho desenvolvida por intermédio da cooperação dos trabalhadores aparece como força produtiva do capital, o que faz da cooperação uma forma específica do processo de produção capitalista em contraste com o processo de produção de trabalhadores isolados, independentes ou mesmo associados livremente.

Como vemos, a cooperação apresenta-se como um elemento fundamental para a consolidação da hegemonia burguesa. Isso tendo em vista que,

[...] o conceito de hegemonia em Gramsci ressalta a capacidade da classe dominante de obter e manter seu poder sobre a sociedade pelo controle que mantém sobre os meios de produção econômicos e sobre os instrumentos de repressão, mas, principalmente, por sua capacidade de produzir e organizar o consenso e a direção política, intelectual e moral dessa sociedade. A hegemonia é, ao mesmo tempo, direção ideológico-política da sociedade civil e combinação de força e consenso para obter o controle social (ACANDA, 2006, p. 178). 
Nesse sentido, é importante também ressaltar que a hegemonia do capital não se constituiu apenas no plano econômico, mas também no político e cultural.

Por enquanto, ressaltamos que as relações de cooperação pressupõem as configurações do trabalho em determinado tempo histórico, não se tratando de uma "forma fixa". Com isso, lembramos que "[...] a produção de valores-de-uso não muda sua natureza geral por ser levada a cabo em benefício do capitalista ou estar sob seu controle" (MARX, 2008, p. 211). Desta forma, por mais que o caráter vigente do trabalho na realidade contemporânea seja o alienado (abstrato), voltado para as neces-sidades de acumulação do capital, o trabalho, por outro lado, não deixa de ser fonte de satisfação das necessidades humanas (útil e concreto), fundamental para o desenvolvimento das potencialidades da espécie humana, do ser social.

Sob essas contradições, o trabalho e, portanto, a cooperação (como também todas as objetivações humanas derivadas do trabalho em seu aspecto ontológico) carregam consigo a força motriz que, por um lado, pode intensificar ainda mais a alienação e, por outro, tem a capacidade de desencadear e fortalecer possíveis transformações que viabilizem uma nova hegemonia de classe.

\section{O MST E A COOPERAÇÃO AGRíCOLANA REALIDADE BRASILEIRA}

Remetendo-nos à realidade do Brasil, com suas particularidades históricas, sabemos que o desenvolvimento do Capitalismo deu-se de forma bastante peculiar, sendo atrelado substancialmente ao caráter agrário da sociedade brasileira, atravessado por relações conservadoras, escravocratas e de heteronomia, subsidiando o desenvolvimento desigual e combinado (FERNANDES, 2007). A agricultura foi, dessa forma, a base do avanço do Capitalismo no país, desde o período de colonização, viabilizando historicamente a acumulação de capital no âmbito do comércio e da indústria. Atualmente, o processo caracterizado pela “primarização da economia” (PETRAS; VELTEMEYER, 2009) nos países latino-americanos (que, de antemão, é alvo de polêmicas e divergências), nos faz perceber esse fenômeno ainda como central, o que demonstra o permanente interesse do capital na questão fundiária. 
Conforme já explicita lamamoto (2007), a questão agrária no país é decisiva para a compreensão das formas históricas assumidas pelo Estado "[...] mediante os interesses de classes vinculados à propriedade territorial na composição política do poder interferindo nas grandes transformações operadas na vida da nação" (IAMAMOTO, 2007, p. 136).

Dessa forma, a conjuntura brasileira vem sendo caracterizada, nos últimos anos, pelo avanço do agronegócio², ocupando grandes extensões de terras com vantajosos recursos naturais. Essa situação é marcada por alguns aspectos, tais como: a crescente concentração de áreas produtivas; intensificação da expropriação e exploração do trabalho na agricultura, inclusive com a presença de relações análogas ao trabalho escravo; avanço de grilagens de terras públicas; aumento de desastres e crimes ambientais, além de contaminação do solo devido, principalmente, à grande quantidade de uso de insumos e defensivos químicos; ascensão de políticas assistencialistas e compensatórias, por parte do Estado, voltadas para os trabalhadores do campo; sucateamento dos órgãos públicos responsáveis pela política agrária; desmoralização e criminalização das lutas sociais.

Diante de tal realidade, percebe-se que a reforma agrária no país não tem tido avanços. Segundo dados do último Censo Agropecuário, elaborado pelo Instituto Brasileiro de Geografia e Estatística (IBGE, 2006), a agricultura familiar tem, atualmente, apenas $24,3 \%$ da área agrícola. Além de ter menos terras, essa agricultura tem menos recursos públicos como suporte de suas atividades. Recebeu cerca de 13 bilhões de reais em 2008 contra, aproximadamente, 100 bilhões repassados ao agronegócio. Os dados demonstram a permanência do velho quadro da concentração fundiária no país, pois apontam que, enquanto as pequenas propriedades (com menos de 10 hectares) ocupam apenas 2,7\% da área ocupada por estabelecimentos rurais, as grandes propriedades (com mais de 1000 hectares) ocupam $43 \%$ da área total. O que torna os

\footnotetext{
"O agronegócio "[...] consorcia de forma mais contundente a fusão de interesses entre setores agropecuários, industriais e financeiros, nos mais diferentes ramos e cadeias produtivas" (THOMAZ JR., 2008, p. 276). E, portanto, uma nova forma de latifúndio com uma amplitude que concentra e domina tanto a terra como também a tecnologia de produção, e as políticas de desenvolvimento.
} 
números assustadores é o fato das pequenas propriedades representarem $47 \%$ do total de estabelecimentos rurais, enquanto os latifúndios correspondem a apenas 0,91\% desse total.

Nesse contexto, percebemos a marca das lutas e resistências daqueles que vivem de seu trabalho. Fazemos referência às ações desenvolvidas pelo MST, desde a sua fundação, em 1984, até hoje, particularmente no âmbito da organização produtiva. Essas ações passam a ter como eixo central a cooperação entre os produtores que vivem e trabalham tanto nas terras desapropriadas para fins de reforma agrária (assentamentos rurais) como naquelas áreas ocupadas pelos trabalhadores no processo de luta como tática política para exigir a realização da reforma agrária (acampamentos rurais). O conjunto dessas experiências de cooperação na produção dirigidas por integrantes do MST nas mais diversas regiões do país têm constituído a denominada cooperação agrícola.

O caminho percorrido, até então, na construção dessa estratégia é marcado por alguns aspectos, tais como: necessidade de mecanizar as lavouras; mudança de padrão técnico do trabalho; falta de políticas públicas permanentes de incentivo à produção e comercialização; necessidade de autossustentação e superação do sistema de lotes individuais, fortalecendo a organização política e a produtividade nas áreas desapropriadas.

É importante destacar que a estratégia da cooperação agrícola sofre continuamente avanços e recuos que dependem da conjuntura política e econômica da realidade do país. No período de 1986 a 1990, o MST passa a organizar a produção nas comunidades a partir das cooperativas e/ou associações. A proposta era reunir de 50 a 100 famílias que queriam se organizar por meio do “[...] laboratório organizacional". Em um curto período, era introduzida a divisão do trabalho em decorrência da necessidade de elevar a produtividade do assentamento e a "[...] consciência social do camponês" (STÉDILE; FERNANDES, 2005, p. 98).

Diante de alguns limites relacionados tanto ao método político-organizativo quanto ao alcance das ações do MST, ainda restritas à região do Sul do país, houve uma maior compreensão sobre o processo de cooperação que superava a existência das cooperativas e passava a iniciar-se no próprio acampamento com a forma- 
ção de grupos de produção coletiva. Nessa trajetória, os trabalhadores experimentaram diversas formas de cooperação desde as mais simples, como o mutirão, até formas mais complexas, como a organização de uma cooperativa agropecuária e de uma agroindústria por meio de associações, grupos coletivos e/ou núcleos de produção nas agrovilas. Vejamos a caracterização das experiências no exemplo abaixo:

O primeiro trabalho coletivo que nós tivemos aqui foi uma horta [...]. Aí, quando a gente queria comprar alguma coisa, um objeto da gente, a gente ia e comprava pra uma, depois comprava pra outra. A gente comprava garrafa, depois cadeira, depois a gente fez uma campanha de filtro [...]. E assim a gente ia fazendo os trabalhos coletivos [...]. Depois desses trabalhos, quando os coqueiros foram crescendo e crescendo, foi desativando o trabalho da horta. Aí as pessoas passaram a ser agente de saúde, o outro foi na educação... E eu e mais outra companheira aqui fiquemos trabalhando em corte e costura, $[\ldots]$ trabalhemos 10 anos pela Cooperativa [...].Nós ganhava só uma ajuda de custo e o outro ficava com a Cooperativa [...] nós vendia as roupa ao povo da comunidade e aí depois nós saímos, mas nós nunca se esquecemos do coletivo. Aí agora tem os coletivos [...]. Tem o dia da semana pra eles trabalharem que é 5 a feira, mas qualquer outro dia que precisar trabalhar, eles tão trabalhando [...]. E aí nós temos um grupo de mulher que ainda não acabou-se, né, quando a gente quer comprar rede, lençou [...]. Na raspação de mandioca, [...] tem dia que a gente encontra de 25 pessoas raspando mandioca na casa de farinha, as jovens, quando elas chegam da escola, do trabalho, aí vai todo mundo pra lá [...]. Agora teve uma derruba do coco, aí eles tiram a parte deles e tiram a parte da cooperativa [...] (Entrevistada 09 - Liderança local e membro da Associação do Assentamento).

Todo esse processo possibilitou a expansão do Movimento para as demais regiões do país, como o Nordeste. No Ceará, por exemplo, em 1989, foi realizada a primeira ocupação com a participação de 300 famílias na antiga Fazenda São Joaquim, localizada nos municípios de Madalena e Quixeramobim. A área, 
onde, atualmente, está localizado o Assentamento 25 de Maio, completa 23 anos de desapropriação com cerca de 425 famílias, sendo considerada, segundo os dirigentes do MST no estado, um polo produtor de ovinos, bovinos e de mamona da região.

Já na década de 1990 aos anos 2000, com o avanço doNeoliberalismo, diversos "ajustes" na política econômica e financeira monitorados por agências multilaterais incidem fortemente sob as organizações da classe trabalhadora. Com a política iniciada pelo governo de Fernando Collor, a agricultura ficou praticamente sem políticas públicas. Essa conjuntura fomentou o debate no MST acerca da criação de centrais de cooperativas gerais como forma de aglutinar as cooperativas e associações, assegurando a organização política e produtiva dos trabalhadores rurais.

Foi, portanto, nesse mesmo período que ocorreu a fundação de quatro cooperativas centrais estaduais junto com a Confederação das Cooperativas de Reforma Agrária do Brasil (CONCRAB). Nesta instância, legalmente, participariam apenas os sócios de associações ou cooperativas, isto mediante um trabalho organizativo em torno do Sistema Cooperativista dos Assentados (SCA). Foi uma época de consolidação das agroindústrias, um momento de "[...] maior amadurecimento da CONCRAB" (STÉDILE; FERNANDES, 2005, p. 106), que passa a contemplar diversos estados, como o Ceará.

Em contrapartida, as empresas, inclusive multinacionais, em aliança com os grandes proprietários de, terra passam a se reorganizar amplamente na agricultura, constituindo e consolidando o agronegócio. Os setores da burguesia nacional, representados por organizações como a União Democrática Ruralista (UDR) e a Confederação Nacional da Agricultura (CNA), além de fortalecer tal aliança, tencionam as políticas estatais voltadas para a agricultura familiar. Essa realidade favoreceu o investimentona chamada "reforma agrária de mercado".

Segundo Stédile e Fernandes (2005), durante oito anos, os trabaIhadores sofreram as consequências do modelo econômico neoliberal consolidado pelo governo do presidente Fernando Henrique Cardoso, que provocou graves danos a quem vive no campo, fazendo crescer a pobreza, a desigualdade, o êxodo rural, e a fal- 
ta de trabalho e de terra. Tal conjuntura incidiu sobre a organização do MST; sua força político-ideológica; e, consequentemente, suas conquistas econômicas.

Particularmente nos anos 2000, com a vitória eleitoral do Partido dos Trabalhadores (PT) para presidência da República, as expectativas em relação aos avanços na reforma agrária depararam-se com condições adversas, apontando para a consolidação de um governo de composição de classes com a presença relevante de setores da burguesia industrial e financeira, o que inviabilizou o avanço esperado, especialmente nas reformas de base, como a agrária, valorizando o agribusiness (MOVIMENTO DOS TRABALHADORES RURAIS SEM TERRA, 2008).

Levando em consideração a autonomia (relativa) das organizações políticas, esse processo, ao mesmo tempo em que enfraquece a luta dos trabalhadores, para o caso específico do MST, oferece condições também para um maior amadurecimento político que possibilita a compreensão tanto da necessidade de ampliar o arco das alianças de classe como dos limites da disputa eleitoral e da governança nos marcos da "democracia" burguesa para gerar mudanças significativas na estrutura econômica, especialmente no âmbito da agricultura.

Como já vimos, conforme apresentam os dados do último Censo Agropecuário (IBGE, 2006), as ações e os investimentos públicos nos últimos anos foram canalizados para a grande produção capitalista. Essa situação direcionou um conjunto de estratégias políticas contra o agronegócio encaminhadas em ocasião do quinto e último Congresso Nacional do MST, em 2007. Deliberações no âmbito da construção de um modelo de produção pautado na luta por uma “[...] reforma agrária popular" (MOVIMENTO DOS TRABALHADORES RURAIS SEM TERRA, 2009, p. 8), na cooperação agrícola e na agroecologia foram centrais.

Como vemos, essa trajetória aponta uma série de entraves e desafios para o desenvolvimento de ações no âmbito da cooperação agrícola, tornando-se central nas discussões e elaborações nos diversos espaços de formação e organização do Movimento. Fruto desse processo, atualmente, há uma concepção hegemônica de cooperação que respalda os trabalhos desenvolvidos pelos trabaIhadores nas áreas onde atuam. 
Tal concepção, presente nos principais documentos internos do MST, é orientada para o "desenvolvimento de valores humanistas e socialistas", buscando vincular a cooperação a um projeto estratégico, que vise à mudança da sociedade. Para isto, "[...] deve organizar os trabalhadores não só para produzir, mas também para a luta e resistência ao capitalismo" (MOVIMENTO DOS TRABALHADORES RURAIS SEM TERRA, 2008, p. 55). Assim, a cooperação é compreendida como um processo e os trabalhadores envolvidos devem ter a clareza de que, na medida em que acontecem determinadas condições objetivas, a cooperação precisa mudar de forma e avançar. "Sem este salto de qualidade, a forma entra em crise, estagna e tende a quebrar" (CONCRAB, 2007, p. 13).

Nesse sentido, a cooperação trabalhada e reivindicada pelo MST tem, portanto, razões econômicas (garantia de sustentabilidade das famílias); razões sociais (melhoria na qualidade de vida, acesso a políticas públicas e benefícios sociais); e razões políticas, ou seja, funciona como "ferramenta" que permite a resistência aos efeitos do Capitalismo, daí a "necessidade de massificá-la" (CONCRAB, 2007).

As experiências de cooperação adquirem um caráter político estratégico, pois nos vincula a um projeto político de sociedade que desejamos construir, tornando estas experiências os sinais concretos de que é possível organizar a sociedade com outros princípios sociais, políticos e econômicos (MOVIMENTO DOS TRABALHADORES RURAIS SEM TERRA, 2008, p. 5).

As relações de produção mediadas pela cooperação na agricultura, na perspectiva da cooperação agrícola, têm como objetivo, portanto, superar tanto as relações tradicionais de trabalho, sustentadas apenas sob a base familiar, como aquelas típicas capitalistas de exploração e alienação, que tem, hoje, como principal expressão o agronegócio.

O nosso objetivo [...] é uma etapa superior aos modos camponês típico e capitalista [...]. Vemos a divisão do trabalho ligada ao desenvolvimento técnico das forças produtivas que existem na sociedade. Esse é um aspecto. O outro é que há alguns casos de assalariamento em algumas cooperativas [...]. Não é, portanto, uma relação social predominante [...] do ponto de vista econômico, a renda da produção 
é dividida entre todos. Isso nem o capitalismo nem o camponês fazem. Aí está a garantia de que todos vão se beneficiar com o avanço técnico que houver naquela unidade produtiva [...]. Acho que vamos criar uma outra interpretação social do trabalho no campo (STÉDILE; FERNANDES, 2005, p. 110-112).

Essa proposta de cooperação na produção, como vimos, tem, para o MST, o grande diferencial em associar a produção cooperada à luta política e a utilização de uma matriz produtiva antagônica àquela hegemônica.

\section{AS PARTICULARIDADES DA COOPERAÇÃO AGRÍCOLA NO CEARÁ}

Antes de tudo, lembramos que o Ceará, assim como toda a região Nordeste, é partícipe da "[...] divisão regional do trabalho no conjunto do território nacional” (OLIVEIRA, 2008, p. 163). Assim, o desenvolvimento do Capitalismo no estado, com o estabelecimento de relações econômicas e políticas particulares, imprime desafios e impasses na construção de novas relações de trabalho e produção na ótica dos trabalhadores.

O Ceará, colonizado do sertão para o litoral, teve a pecuária extensiva como uma das atividades de maior envergadura no processo de ocupação territorial. Isso muito embora entre os séculos XIX e XX a cultura do algodão tenha representado uma das principais atividades econômicas do estado, período de mudanças (especialmente na estrutura fundiária e nas relações sociais que as sustentam) motivadas pela inserção da economia cearense no circuito mundial e da forte industrialização nos centros urbanos.

Para Andrade (1998), no sertão, a escravidão não teve grande repercussão econômica. Isso, no entanto, não elimina da nossa história o forte traço de subserviência nas relações entre as classes que foi, e continua sendo, intermediado pela propriedade privada, mais precisamente, pelo domínio da terra. É nessas mesmas terras que o fenômeno climático da seca passa a atravessar todas as dimensões da vida coletiva, desde o campo até as cidades, tornando-se um "fenômeno social complexo" constitutivo da história do Ceará.

A expansão da agricultura no estado estabelece relações fundamentadas na submissão e dependência pessoal com o proprie- 
tário, generalizando a cobrança de "[...] pagamento de renda pelo uso da terra que, na sua maioria, era feito através do trabalho obrigatório e de parte do produto, geralmente a meia" (DINIZ, 2008, p. 44). Nessa realidade, portanto, conformaram-se relações de produção fundamentalmente "híbridas". O problema de mão-de-obra neste período "[...] travou séria batalha entre trabalho escravo e o assalariado" (ANDRADE, 1998, p. 95).

Sob essa ótica, a experiência brasileira, particularmente do Nordeste, revela que o próprio capital, dentro de suas contradições, pode ser realizado mediante "[...] relações de trabalho e de produção não-capitalistas para produzir o capital" (OLIVEIRA, 2001, p. 19). Desta forma, "[...] o capital sujeita a renda da terra produzida pelos camponeses à sua lógica, realizando a metamorfose da renda da terra em capital" (OLIVEIRA, 2001, p. 479). Nesse sentido, para o autor, o trabalho familiar exerce função relevante para a reprodução ampliada do capital, repercutindo até os dias de hoje. Sobre isto, basta lembrar a coexistência desigual entre a produção do agronegócio, voltada excepcionalmente para a exportação, e a da agricultura familiar, destinada ao consumo interno, como muito bem demonstra o último Censo Agropecuário (IBGE, 2006).

Destacamos também o papel da estreita relação existente entre os latifundiários, os "coronéis", e os governantes no desenvolvimento de "políticas modernizantes", especialmente via incentivos ficais e crédito, tão presentes e atuais ${ }^{3}$, viabilizando as mudanças nas relações de trabalho no sertão (DINIZ, 2008, p. 138), desde a mudança no regime de parceria até a introdução do assalariamento. Com isso, o produtor que se "[...] assalariou passou a sofrer um duplo processo de exclusão: era excluído

${ }^{3}$ Reportando-nos à história mais recente, o Ceará vivenciou processos significativos mediante as intervenções dos "governos das mudanças", representados, em suma, pelos três governos de Tasso Jereissati, com destaque para maior modernização da agricultura, forte incentivo à industrialização e tentativa de interiorização dos projetos produtivos já capitaneados pelo capital transnacional, transformando a estrutura fundiária do estado e as consequências das secas. Esse conjunto de mudanças pode ser considerado o "laboratório" da política econômica neoliberal que se consolidará no Brasil a partir da década de 1990. Dentre as contradições geradas, toma relevância um contingente de trabalhadores rurais "sem-terras" passando a ser sujeito central de dois processos que se acirram nesse período: o êxodo rural e a luta social. 
das garantias trabalhistas legais válidas para os trabalhadores urbanos e perdia o direito de parte dos benefícios criados na terra do patrão" (DINIZ, 2008, p. 74), o que agravou os problemas da estrutura fundiária, forçando condições adversas para os trabalhadores rurais.

Assim, a construção do tecido social do estado é caracterizada por relações sociais próprias de um modelo de produção que promove níveis cada vez maiores de concentração de renda e terra. Isso decorre em medidas incongruentes com a ação das políticas públicas que carregam em si o forte caráter da "modernização conservadora": "políticas pobres para pobres" de um lado, e, de outro, grande incentivo ao empresariado cearense, brasileiro e multinacional.

A particularidade da formação social do Ceará e das características geográficas de seu território implica diretamente no processo de organização produtiva nos assentamentos rurais vinculados ao MST no estado. Sobre a realidade dessas áreas, ressaltamos, antes de tudo, que, por mais precária que seja a atual política de reforma agrária, é inegável as diferenças entre antes e depois da conquista da terra na vida dos trabalhadores. Observemos os depoimentos a seguir:

Nós vivia como agregado. Vamos supor, nós pagava uma renda e aí nós se juntemos, todo mundo, e queria uma libertação pra viver numa terra, pra melhor pra gente, né. Nessa época, quando eu brocava, nessa época era só dois meninos, era 50 passos que nós tinha direito. Aí eu tinha que pagar ainda renda, era um alqueire de milho. Depois que nós desapropriemo a terra, aí nós podia brocar uma quadra, uma quadra e meia... Desde lá foi assim (Entrevistado 05 - Liderança local e membro da diretoria da Cooperativa).

No tempo que era do patrão, a gente não tinha nem farinha. A gente é um produtor e nem farinha a gente tinha pra comer. E depois que a área foi desapropriada que agora a gente vive nessa terra, mudou bastante. Primeiro os filhos da gente começou a estudar, né. Aí a gente começou a lutar por uma terra melhor. Uma terra que fosse coberta da produção da gente [...] (Entrevistada 09 - Liderança local e membro da Associação do Assentamento). 
A desapropriação da terra representa para a maioria dos trabaIhadores uma melhoria na qualidade de vida e nas condições de trabalho. Isto devido, principalmente, ao acesso a terra e ao fim da figura do patrão, o que, para os produtores, significa uma "autonomia", antes inexistente, na produção. E, para outros, com a intermediação da Cooperativa, houve maiores condições de autossustentação local e possibilidades de trabalho e produção coletivos, antes inexistente.

Entretanto, outros aspectos são importantes para entender a particularidade dessa realidade:

1) Segundo os dirigentes do Movimento, uma das diferenças existentes no Ceará em relação ao resto do país é exatamente o fato de não haver o loteamento individual das terras desapropriadas, existindo apenas a concessão condominial para atender a forma coletiva da produção, trabalho e propriedade (INCRA, 2000), o que implica favoravelmente à cooperação na produção e, consequentemente, no fortalecimento da organização política. Isto tendo em vista que a "relação individualizada e individualizante com a propriedade determinará o modo de agir e de pensar" dos trabalhadores e "[...] se tornará cada vez mais rígida quanto maior for o tempo de duração dessa relação" (MOVIMENTO DOS TRABALHADORES RURAIS SEM TERRA, 2006, p. 7).

Sobre as particularidades tem o fato do estado do Ceará não trabalhar, e sempre o Movimento pautou desde o início, essa questão de não organizar o assentamento por lotes. Sempre é trabalho de forma coletiva, a área pertence a todos e não tem essa questão do loteamento que, esse é um dos principais diferenciais do Movimento a nível nacional que nenhum outro estado tem essa diferença, né. [...]. Formalmente junto ao INCRA essa área não é loteada, individualizada. Não existe nenhum documento que tal família tem tantas quantidades de hectares. Claro, quando eles vão desapropriar, eles fazem a expectativa de quanto, né, pelo fato dos lotes fiscais, mas não há essa divisória legalmente no documento do INCRA (Entrevistado 02 - Dirigente Estadual do MST do Ceará). 
2) No âmbito da organização da produção, essas áreas, em suma, baseiam-se em um modelo chamado "misto" 4 . Este modelo é discutido coletivamente entre os trabalhadores que estabelecem normas de utilização de determinadas terras e equipamentos de forma coletiva, viabilizando a coexistência das formas de trabalho individual, fundamentado basicamente na agricultura familiar, e coletiva, com grupos e coletivos de produção que, geralmente, são intermediados por uma associação ou cooperativa.

Para o Movimento dos Trabalhadores Rurais Sem Terra (2008), é fundamental combinar atividades produtivas das famílias com áreas de produção coletivas administradas em conjunto por meio de grupos e coletivos, pois permite um avanço na organização da produção familiar, exigindo um "grau de consciência mais elevado" (MOVIMENTO DOS TRABALHADORES RURAIS SEM TERRA, 2008, p. 33). A organização produtiva coletiva por intermédio da cooperação agrícola é "um elemento estratégico, justamente, por criar condições para o melhor desenvolvimento do trabalho social, indo além do trabaIho familiar individual e da propriedade privada" (MOVIMENTO DOS TRABALHADORES RURAIS SEM TERRA, 2006, p. 7);

3) Outro aspecto que influencia diretamente a produção e a organização do trabalho nessas terras é a localização e as condições geográficas. Isso porque a maioria das áreas, cerca de 400 assentamentos rurais com 26 mil famílias (DINIZ, 2008), está localizada no sertão cearense e ainda não têm acesso a políticas públicas que ofereçam condições para suprir as necessidades de produção dos trabalhadores.

Somos o estado que mais está dentro do semi-árido. $93 \%$ do nosso estado está dentro do semi-árido. E, com certeza, $99 \%$ dos assentamentos estão dentro do semi-árido. [...] A gente dificilmente consegue fazer assentamentos na região litorânea, na zona costeira [...] porque é área nobre. Lá dentro está loteado pro capital internacional, as empresas que estão interessadas no turismo, na carcinicultura e tal. [...]Por quê que nós

\footnotetext{
4 "Ao longo do tempo, o Movimento foi organizando as formas de cooperação do uso da terra a partir de grupos de produção semi-coletivos ou mistos. Esse sistema possui características intermediárias entre o modelo individual e o coletivo, sendo a posse da terra coletiva, sem loteamento e o uso da mesma de maneira tanto socializada como individual"(A LUTA..., 2009).
} 
não temos uma situação econômica melhor nas famílias? [...]. Muitas vezes a gente acha que conquistou a terra, mas é caro! É caro você pegar sua área, a terra lá que você conquistou, e botar ela pra produzir. [...]. No nosso semi-árido, nos sertões do Ceará, só ter a terra e coragem de trabalhar não basta (Entrevistada 01 - Dirigente do Setor de Produção do MST no Ceará).

Eis a atualidade da "indústria da seca". Enquanto isso, as terras de maior potencial econômico, geralmente localizadas na zona costeira e serrana ou que alcançam os perímetros irrigados do estado, são regiões de expansão do agronegócio e da especulação imobiliária.

Segundo a Agência de Desenvolvimento do Estado do Ceará (ADECE), o estado assume, hoje, o patamar da terceira maior economia do Nordeste brasileiro com um PIB que corresponde a mais de 50 bilhões de reais. As exportações do Ceará chegaram a US\$ 1,27 biIhão em 2008, ficando atrás somente dos estados da Bahia e do Maranhão. Essa realidade é respaldada na política desenvolvida tanto pelo governo federal como estadual por meio de grandes projetos e investimentos públicos, via Banco Nacional de Desenvolvimento Econômico e Social (BNDES), como parte integrante do Programa de Aceleração do Crescimento (PAC).

Contraditoriamente ao que clama o discurso do "desenvolvimento", chama atenção, na primeira página do Caderno de Negócios do Jornal Diário do Nordeste, em 14 de julho de 2010, a seguinte notícia: "Ceará é o quinto em proporção de pobres no país", mesmo tendo tido queda na taxa de pobreza absoluta para $49 \%$ da população local no intervalo de 1995 a 2008, segundo pesquisa divulgada pelo Instituto de Pesquisa Econômica Aplicada (IPEA, 2010).

Nessa lógica, a “onda” de crescimento econômico e geração de empregos nada mais é que a (re)constituição da dinâmica capitalista na esfera local, permitindo uma fase expansiva do capital em que a produção de riqueza gera incessantemente o seu contrário, a pobreza. Talvez isso possa explicar o avanço da concentração de terras no Ceará concomitante à expansão desses grandes projetos, particularmente aqueles voltados para o agronegócio.

Observamos, então, que os projetos "estruturantes" priorizam o financiamento, por excelência, da produção e do escoamento 
do grande capital. Vejamos abaixo os subsídios que a entrevistada nos apresenta sobre tal situação.

A transposição do São Francisco que era o mais importante [...]. A conversa do governo era que os 12 milhões de nordestinos iria ter água, mentira! Vai ter água os 12 proprietários de fruticultura que estão às margens do perímetro irrigado [...]. Nós não estamos nessa região, nem vamos estar [...]. Vai passar dentro de comunidades que têm necessidade de água, mas essa comunidade vai ter acesso a essa água? Duvido. Nós já fomos presos porque usamos a água do Canal do Trabalhador, na época do Ciro [...]. A transnordestina que tá aí fazendo as estradas que vai passar por dentro dos sertões, também [...] mas as estradas dos assentamentos tá lá esburacadas. No inverno nós não anda. Nós não temos como organizar o processo de produção pra poder se beneficiar desse processo dessas estradas [...]. Então, em vez dessas mega obras contribuir, elas vão prejudicar. Por quê? Na medida que eu construo uma grande obra, eu tiro as famílias, desaproprio. Aí a água chega e as famílias saem. Quando a água chega, chega também a estruturação dos perímetros irrigados que já está destinado pra quem tem dinheiro [...]. Então uma barragem dessa que desagrega não sei quantas mil famílias, daria pra você fazer 10 barragens menores que favorecia mais as pessoas [...]. Nós não temos política de assentamentos. Nós temos projetos de assentamentos que, por si só, não se liga as políticas [...] (Entrevistada 01 - Dirigente do Setor de Produção do MST no Ceará).

Tudo isso nos diz o quanto são grandes as contradições e os desafios postos à classe trabalhadora e a suas organizações que ousam desenvolver experiências de cooperação na ótica da resistência, do controle dos produtores e da construção de uma nova hegemonia.

\section{CONSIDERAÇÕES FINAIS}

O percurso que fizemos durante nossa investigação nos traz diversos elementos que legitimam a realidade analisada enquanto síntese de múltiplas determinações historicamente construídas que incidem particularmente sobre a relação, priorizada por nós, entre a cooperação na produção e a construção de hegemonia. 
Constatamos a existência na realidade agrária cearense de diversos entraves e limites aos trabalhadores rurais vinculados ao MST em construir estratégias de organização produtiva que fortaleça o controle desses e permita consolidar a cooperação agrícola nos assentamentos e acampamentos rurais. Essa condição reverte-se em uma série de situações presentes na vida cotidiana desses trabalhadores que tendem a uma gradativa perda da centralidade da produção e do trabalho coletivos e a um clima geral de desânimo e descrédito em relação às ações no âmbito da cooperação agrícola.

Os motivos pelos quais essa situação vem se conformando são, muitas vezes, relacionados ao crescente individualismo e diferenciação social existente dentro dos próprios assentamentos rurais; à falta de políticas públicas que respondam as reais necessidades dos trabalhadores nessas áreas; entre outros fatores internos e externos. Porém, ressaltamos um fator que, para nós, tem maior centralidade e capacidade de articular todos os outros: a subordinação inevitável à lógica do mercado e, consequentemente, às leis do capital, o que, frente às condições materiais precárias e necessidades imediatas postas na vida dos trabalhadores "sem-terra", tende a fortalecer a produção e o trabalho individual (ou assalariado) com seu potencial de garantir resultados mais imediatos. Ou seja, tais fatores conformam o controle, ou melhor, a atual hegemonia do capital nas terras desapropriadas para fins de reforma agrária.

Essa constatação nos remete a reafirmar a importância do latifúndio para desenvolvimento do Capitalismo no Brasil, hoje marcado por alianças entre os diversos setores da burguesia nacional e internacional, e pela hegemonia da "política de conciliação de classes". Isto nos dá a devida certeza de que um dos entraves na cooperação da produção sob o controle dos trabalhadores rurais foi, e continua sendo, os impasses no âmbito da realização da reforma agrária no país. Isso porque a reforma agrária brasileira demandará mudanças mais profundas na sociedade.

Entretanto, lembramos que o desenvolvimento histórico do Capitalismo é permeado por contradições: ao mesmo tempo em que se (re)produzem condições de hegemonia do capital, criam-se também condições que apontam para sua superação. 
Assim, observarmos que a forma de exploração vigente que se expande nas regiões em que vivem os produtores beneficiados pela "política de assentamentos rurais" pode trazer à tona o verdadeiro agente da exploração, possibilitando que se gere uma "nova" contradição (de um lado, a intensificação do pauperismo e, de outro, o fulgor e a capacidade produtiva da grande e moderna propriedade) e, consequentemente, um maior acirramento da luta de classes e amadurecimento político desses trabalhadores que podem passar da "plena adesão" ao agronegócio para a "grande aversão".

Não podemos negar, então, os passos que foram dados, implicando grandes diferenças na vida desses produtores, como: 1) as experiências dos grupos de trabalho coletivo, mesmo não exercendo papel central na vida dos produtores; 4) a apropriação coletiva de boa parte da terra e o seu não loteamento; 5) a apropriação do excedente, em geral, da produção (seja coletiva ou individual) pelo próprio trabalhador e sua família. Assim, não podemos cometer o equívoco de identificar as relações construídas no âmbito da cooperação agrícola somente como uma simples, unilateral, reprodução da sociabilidade capitalista.

Desta forma, mesmo diante de tantos percalços, é necessário o fortalecimento de experiências de cooperação que possam alterar a cínica coexistência entre a agricultura familiar tradicional e o agronegócio. Por hora, é imprescindível o desenvolvimento da produção coletiva, potencializando-a e diversificando-a com, por exemplo, as agroindústrias. Para isso, o acesso aos meios de produção junto ao desencadeamento de ações organizadas coletivamente que subsidiem a comercialização dos produtos torna-se uma demanda emergencial.

Eis, então, a possibilidade histórica permanentemente presente na vida dos produtores que vivem e trabalham nesses territórios em disputa. Entendemos, no entanto, que a viabilidade de uma nova hegemonia só é possível pela mediação da política, da capacidade política de organização e da mobilização da classe como um todo, fazendo com que a fração dos produtores, antigos moradores, passe a se constituir enquanto sujeito político coletivo, com uma visão de mundo em comum. Daí a invia- 
bilidade de se operar essa nova hegemonia sem estratégias que conjuguem ações tanto no âmbito produtivo como político. No caso, a cooperação produtiva dos trabalhadores sem um projeto político que a sustente dificilmente alcançará patamares que supere a reprodução do velho.

\section{REFERÊNCIAS}

ACANDA, Jorge Luís. Sociedade civil e hegemonia. Rio de Janeiro: UFRJ, 2006.

A LUTA para além da terra. Jornal sem Terra, São Paulo, n. 290, mar. 2009. Disponível em <http://www.mst.org.br/jornal/290/ estados>. Acesso em: 12 jan. 2011.

AMARAL, Ângela Santana do. A categoria sociedade civil na tradição liberal e marxista. In: MOTA, Ana Elizabete (Org.). O mito da Assistência: ensaios sobre Estado, política e sociedade. Recife: UFPE, 2006.

ANDRADE, Manuel Correia de. A terra e o homem no Nordeste: contribuição ao estudo da questão agrária no Nordeste. Recife: UFPE, 1998.

BEHRING, Elaine Rossetti. Brasil em Contra-reforma: desestruturação do Estado e perda de direitos. São Paulo: Cortez, 2003. BOTTOMORE, Tom. Dicionário do pensamento marxista. São Paulo: Jorge Zahar, 2001.

BRASIL. Programa das Nações Unidas para o Desenvolvimento. 2010. Disponível em: <www.pnud.org.br>. Acesso em: 13 jan. 2011. CEARÁ (CE). Agência de Desenvolvimento do Estado do Ceará. 2011. Disponível em: <http://www.adece.ce.gov.br>. Acesso em: 12 jan. 2011.

CEPAL. Panorama Social da América Latina. 2009. Disponível em: <http://www.eclac.org/cgibin/getProd.asp?xml=/publicacio-nes/xml/9/37859/P37859.xml\&xsl=/dds/tpl-p/p9f.xsl\&base=/ tplᄀ-p/top-bottom.xsl>. Acesso em 13 set. 2010.

CONCRAB. Cooperação Agrícola: eixos prioritários de ação, princípios e formas. São Paulo: CONCRAB, 2007. (Caderno de Cooperação, n. 5). 
DINIZ, Aldiva Sales. Trilhando caminhos: a resistência dos camponeses no Ceará em busca de sua libertação. 2008. Tese (Doutorado em Geografia Humana)-Universidade de São Paulo, São Paulo, 2008.

ENGELS, Friedrich. Humanização do macaco pelo trabalho. In: A DIALÉTICA da natureza. 6. ed. Rio de Janeiro: Paz e Terra, 2000.

FABRINI, João Edmilson; MARCOS, Valéria de. Os camponeses e a práxis da produção coletiva. São Paulo: Expressão Popular; UNESP, 2010.

FERNANDES, Florestan.O que é revolução. In: CLÁSSICOS sobre a revolução brasileira. São Paulo: Expressão Popular, 2007.

IAMAMOTO, Marilda Villela. O Serviço Social na contemporaneidade: trabalho e formação profissional. 2. ed. São Paulo: Cortez, 2004.

- Relações sociais e Serviço Social no Brasil: esboço de uma interpretação histórico-metodológica. 26. ed. São Paulo: Cortez: CELATS, 2009.

. Serviço Social em tempo de capital fetiche: capital financeiro, trabalho e questão social. São Paulo: Cortez, 2007.

IBGE. Pesquisa Nacional por Amostra em Domicílio. 2009. Disponível em: <http://www.ibge.gov.br/home/estatistica/populacao/trabalhoerendimento/pnad2009/>. Acesso em: 15 fev. 2010.

. Censo Agropecuário. 2006. Disponível em: <http://www. ibge.gov.br/home/estatistica/economia/agropecuaria/censoagro/2006/agropecuario.pdf>. Acesso em: 15 fev. 2010.

INCRA. Plano de Desenvolvimento Sustentável do Projeto de Assentamento Lagoa do Mineiro. Itarema: INCRA, 2000.

IPEA. Brasil em desenvolvimento: Estado, planejamento e políticas públicas. Brasília: IPEA, 2010.

LUXEMBURGO, Rosa. Reforma ou revolução? (Trad. Lívio Xavier). São Paulo: Expressão Popular, 1999.

MARX, Karl. O Capital: crítica da economia política: Livro I. 3. ed. São Paulo: Nova Cultura, 2008. v. 2. 
MARX, Karl; ENGELS, Friedrich. Ideologia alemã. São Paulo: Expressão Popular, 2009.

MÉSZÁROS, István. A crise estrutural do capital. São Paulo: Boitempo, 2009.

MOTA, Ana Elizabete. Questão social e Serviço Social: um debate necessário. In: MOTA, Ana Elizabete (Org.). 0 mito da assistência social: ensaios sobre Estado, política e sociedade. São Paulo: Cortez, 2008.

MOVIMENTO DOS TRABALHADORES RURAIS SEM TERRA (Brasil). A reforma agrária necessária: por um projeto popular para a agricultura brasileira. São Paulo: MST, 2006.

MOVIMENTO DOS TRABALHADORES RURAIS SEM TERRA (Brasil). Programa de Formação para a Cooperação e Organização dos Assentamentos. São Paulo: MST, 2008. (Cartilha de Apoio I). MOVIMENTO DOS TRABALHADORES RURAIS SEM TERRA (Brasil). Os desafios da luta pela reforma agrária popular e do MST no atual contexto. São Paulo: MST, 2009. (Caderno de debate, n. 1).

OLIVEIRA, Ariovaldo Umbelino de. Agricultura camponesa no Brasil. São Paulo: Contexto, 2001.

OLIVEIRA, Francisco. Elegia para uma re(li)gião: Sudene, Nordeste: planejamento e conflitos de classes. São Paulo: Boitempo, 2008.

PEREIRA, Evelyne Medeiros. Cooperação e hegemonia na dinâmica do capitalismo contemporâneo: a cooperação agrícola e organização política dos trabalhadores rurais na Lagoa do Mineiro/Ceará. 2011. Dissertação (Mestrado em Serviço Social) -Universidade Federal do Pernambuco, Recife, 2011.

PETRAS, James; VELTMEYER, Henry. Dinámica del poder político en América Latina. In: BORGIANNI, Elisabete; MONTAÑO, Carlos (Org.). Coyuntura actual, latinoamericana y mundial: tendencia y movimientos. São Paulo: Cortez, 2009. (Biblioteca latinoamericana de serviço social. Série antologias, v.14).

STEDILE, João Pedro; FERNANDES, Bernardo Mançano. Brava gente: a trajetória do MST e a luta pela terra no Brasil. São Paulo: Fundação Perseu Abramo, 2005. 
THOMAZ JR., Antônio. A classe trabalhadora no Brasil e os limites da teoria: qual o lugar do campesinato e do proletariado? In: FERNANDES, Bernardo Mançano (Org.). Campesinato e agronegócio na América Latina: a questão agrária atual. São Paulo: Expressão Popular, 2008. 